Institute of $\mathbf{F}_{\text {ood and }} \mathbf{A}_{\text {gricultural }} \mathbf{S}_{\text {ciences }}$

\title{
Manual de los Reglamentos del Agua de Florida: Acta de Responsabilidad, Compensación y Respuesta Ambiental Completa ${ }^{1}$
}

\author{
Michael T. Olexa, Laura Minton, Dulcy Miller, y Sarah Corbett ${ }^{2}$
}

\section{Agradecimientos}

Los autores agradecen a Richard Budell de la Oficina de Política del Agua Agrícola del Departamento de Agricultura y Servicios al Consumidor de Florida. Los autores también agradecen a David H. Hammonds, Consultor del Programa de Salud Ambiental, Oficina de Programas de Aguas de Drenaje en el Sitio, del Departamento de Salud de Florida, y a Edward A. Bettinger, Consultor del Programa de Salud Ambiental, Oficina de Programas de Agua del Departamento de Salud de Florida.

\section{Sinopsis}

El Acta de Responsabilidad, Compensación y Respuesta Ambiental Completa (ARCRAC o superfondo), fue aprobada en $1980 \mathrm{y}$ reformada en 1986. Esta autoriza y proporciona un fondo financiero para que la Agencia de Protección Ambiental (APA) investigue y limpie lugares contaminados por substancias peligrosas. La ARCRAC también extiende la responsabilidad de contaminación en el sitio hacia aquellas personas potencialmente relacionadas con el delito, y es una medida fuerte para obligar a las partes responsables a contribuir a los costos de saneamiento.

1. Este es el documento EDIS FE067, una publicación del Department of Food and Resource Economics, Florida Cooperative Extension Service, Institute of Food and Agricultural Sciences, University of Florida, Gainesville, FL. Publicada Noviembre 2002. Por favor visite la página electrónica EDIS en http://edis.ifas.ufl.edu.

2. Michael T. Olexa, es profesor del Department of Food and Resource Economics, Florida Cooperative Extension Service, Institute of Food and Agricultural Sciences, University of Florida, Gainesville, FL; y miembro de Florida Bar; Presidente de Agricultural Law Committee of The Florida Bar; y Director del Agricultural Law Center. Laura Minton, Dulcy Miller, y Sarah Corbett son estudiantes graduadas de Levin College of Law, University of Florida, Gainesville, FL. Filiberto Reyes-Villanueva fue el traductor de la versión en ingles al español.

Esta publicación esta diseñada para proporcionar información precisa, actualizada y autorizada sobre esta material. Sin embargo, ya que las leyes, reglas administrativas y decisiones de la corte, sobre las cuales están basados, están sujetas a revisión constante; algunas partes de esta publicación podrían ser obsoletas en cualquier momento. Esta publicación es distribuida bajo el entendimiento que los autores no están involucrados en ninguna representación legal u otros servicios profesionales, y que la información contenida aquí no debe ser considerada como un substituto de una asesoria legal. Esta publicación no esta completa en proporcionar toda la información para lograr el cumplimiento de las leyes y reglamentos que gobiernan la protección del agua. Por estas razones, el uso de estos manuales por cualquier persona constituye un acuerdo para mantener libre de daño a los autores, al Florida Cooperative Extension Service, al Institute of Food and Agricultural Sciences, y a la University of Florida por cualquier demanda por responsabilidad de daños, o gastos en que pueda incurrir cualquier persona, como un resultado de hacer referencia o confianza sobre la información contenida en esta publicación. Esta publicación fue apoyada financieramente por el Florida Department of Agriculture and Consumer Services.

El Instituto de Alimentos y Ciencias Agrícolas es Un empleador que opera bajo Acción Afirmativa y provee Oportunidades Igualitarias, dedicado a promocionar la investigación, a información educativa y otros servicios, únicamente a los individuos e instituciones que operan baj discriminación sin considerar color, raza, sexo, edad, incapacidad u origen. Para más información sobre como obtener otras publicaciones de la extensión, comuníquese con la oficina de Servicio de Extensión de su condado. Servicio de Extensión de la Florida / Instituto de Alimentos y Ciencias Agrícolas / Universidad de la Florida / Christine Taylor Waddill, Decana. 
La APA ha creado una lista de "substancias peligrosas" las cuales están al alcance de la regulación de la ARCRAC. Además, el acta incluye como referencia todas las substancias o contaminantes peligrosos que están identificados por el ARCR federal, el Acta del Aire Limpio o el Acta del Agua Limpia. Las únicas exclusiones expresas de la cobertura de la ARCRAC son el petróleo (aunque la APA se reserva el poder de clasificar los productos específicos del petróleo como peligrosos) y el gas natural y sintético.

\section{¿Quien Aplica la ARCRAC?}

La APA es y ha sido el principal ejecutor de la ARCRAC, aunque el Presidente esta autorizado para entrar en acuerdos con los estados que deseen aplicar las disposiciones de la ARCRAC. También la APA debe consultar con los estados relevantes y los funcionarios locales, antes de decidir sobre las soluciones para la contaminación en las instalaciones federales, especialmente donde las instalaciones o soluciones seleccionadas están dentro del alcance de la ley estatal ambiental.

\section{¿Quien Investiga las Violaciones de la ARCRAC?}

El administrador de ARCRAC tiene autoridad para empezar investigaciones, donde sea que haya una razón para creer que una liberación ha ocurrido o pueda ocurrir. La APA, o una autoridad estatal o local actuando en acuerdo con la APA, pueden requerir a la persona o entidad bajo investigación, a que les proporcione información acerca de la naturaleza y manejo de todos los materiales peligrosos en el sitio, así como también información relacionada con la capacidad del sujeto para pagar por la limpieza.

La ARCRAC también autoriza entrar, en momentos razonables, a cualquier sitio relacionado con materiales peligrosos y además autoriza la toma de muestras del lugar. Si las solicitudes de la APA son negadas durante la fase de investigación, la APA puede emitir ordenes de acatamiento para obligar la cooperación. La APA puede hacer cumplir las ordenes con multas civiles de hasta $\$ 25,000$ por día.

\section{¿Qué Implica una Limpieza?}

Si las investigaciones confirman que una sustancia peligrosa (o un contaminante con el potencial inminente de ser una amenaza a la salud publica) ha sido o puede ser liberada, la APA puede ejercer una combinación de varias opciones de respuesta. Estas opciones incluyen acción de remoción, acción de reparación o ejecución de la ley. Una acción de remoción es una acción interina inmediata, mientras que la acción de reparación es una medida mas permanente. Las medidas permanentes, efectivas en costo, son fomentadas por la ARCRAC hasta donde sea posible. También la limpieza debe estar de acuerdo con otras actas apropiadas ambientales ya sea federales o estatales. La APA, o el estado en muchos casos, esta facultado para emprender la limpieza, aunque las partes responsables pueden ser autorizadas para iniciar una limpieza privada, si ellas pueden demostrar a la APA que la limpieza será tan efectiva como la propuesta por las medidas de la APA. Esta opción puede ser mucho menos costosa para las partes quienes por otro lado, serian forzados a pagar por cualquier limpieza de la APA.

\section{¿Quién es el Responsable por los Costos de la Limpieza?}

La ARCRAC esta dirigida hacia cuatro tipos de partes potencialmente responsables:

1. los propietarios de los lugares.

2. los operadores de los lugares.

3. los transportistas de substancias dañinas.

4. aquellos que tramitan tal transportación.

Es importante resaltar que los propietarios pueden estar sujetos de responsabilidad aun si ellos compraron sin estar enterados del entierro de las sustancias peligrosas en el lugar. Esta ha sido una fuente de gran interés para los compradores de tierras, que usan créditos hipotecarios bancarios y otros para adquirir la tierra.

La ARCRAC requiere que la ubicación de cualquier sitio que contiene materiales peligrosos sea reportado a la APA. Además, también es requerida 
una pronta notificación, después que ha ocurrido cualquier derrame o liberación de materiales contaminados en el medio ambiente. Las fallas por no reportar cualquiera de estos casos puede resultar en multas y/o penas de prisión que van desde tres a cinco años.

La ARCRAC impone estricta responsabilidad y, por lo tanto, no requiere de un estricto hallazgo de negligencia antes que los castigos puedan ser impuestos. También, la responsabilidad conjunta o por separado permite a la APA obligar a una de las partes, quien pueda ser solo parcialmente responsable del daño, a pagar el costo total de la limpieza. (La regla de la responsabilidad conjunta o por separado, es explicada más en detalle en la sección de Regulación Privada).

Las defensas contra la responsabilidad están limitadas a:

- actos de Dios.

- actos de guerra.

- acciones de una tercera parte.

- defensa del propietario inocente.

- exención por interés de seguridad.

- la aplicación de insecticidas registrados bajo la FIFRA.

La defensa de la tercera parte es permitida solamente cuando alguien es totalmente responsable por el daño, y donde no existe una relación de contrato entre el acusado y la tercera parte. La defensa del propietario inocente se aplica cuando un nuevo propietario no sabia y no tenia razón para saber, que un propietario anterior había contaminado la propiedad. En muchos casos, la responsabilidad puede aplicarse a ambos, al actual y anteriores propietarios, independientemente de la culpabilidad. La exención por interés de seguridad protege a los prestamistas (como los bancos) de responsabilidad, cuando el prestamista no participa en el manejo de la instalación. La persona que aplica insecticidas registrados bajo la FIFRA no están sujetos de responsabilidad bajo la ARCRAC, solo si los insecticidas son aplicados de acuerdo a las instrucciones de las etiquetas.

\section{¿Qué son Auditorias Ambientales?}

Una auditoria es básicamente una evaluación de la condición de la tierra y una apreciación de la consecuente posibilidad, de que el prestamista sea sujeto de algún tipo de acción ejecutoria que pueda perjudicar la seguridad del prestamista. Tal acción puede originarse, por ejemplo, de la responsabilidad que la ARCRAC impone a los propietarios por sustancias peligrosas enterradas en sus tierras. La ARCRAC es aún una amenaza para los compradores inocentes, ya que se aplica aun si la contaminación fue dejada por un propietario anterior y el comprador no tenia conocimiento de ello. Si la auditoria revela que la tierra está de alguna manera "no limpia, la negociación será retrasada inevitablemente hasta que el prestamista este bien seguro de que su interés en la tierra no será devaluado.

\section{Fuente}

Código 42 de los Estados Unidos secciones 9601 a 9675. 